\title{
Miniaturized Ultra Wide Band Microstrip Antenna with Defect Ground Structure for Brain Tumor Detection
}

\author{
Hemant Kumar Gupta ${ }^{1}$, Vikas Maheshwari ${ }^{1}$ and Vandana Vikas Thakery ${ }^{2}$ \\ ${ }^{1}$ Dept of ECE, ASET, Amity University Madhya-Pradesh, Gwalior, M.P., INDIA- \\ 474005 \\ ${ }^{2}$ Dept. of ECE, Madhav Institute of Technology \& Science, Gwalior, M.P., INDIA- \\ 474004 \\ hmnt_gpt@yahoo.co.in ${ }^{1}$,vmaheshwari@gwa.amity.edu ${ }^{1}$ \\ vandana@mitsgwalior.in ${ }^{2}$ \\ Abstract
}

\begin{abstract}
Brain tumour is the largest problem in the world. Few researchers have yorked in that area. In the paper brain tumour is detected by the three differen parameter of the proposed antenna namely return-loss of the antenna, curent density of the brain phantom model with tumour and without tumour and specific absorption rate (SAR) with and without tumour. None of the previous work detects a tumour by thee different parameter simultaneously. Initially the proposed antenngis designed at $2.45 \mathrm{GHz}$ and then applies different technology to make it ultra wide-band. Antenna fiequency is shifted and it become the ultra wide band and gives a bandwidth of $289 \mathrm{GHz} . S_{11}$ parameter of antenna achieved maximum at $7.624 \mathrm{GHz}$ that is $45.76 \mathrm{~dB}$. Found current density of the antenna is $770.6 \mathrm{~A} / \mathrm{m}^{2}$, SAR of the antenna is $2.67 * 10^{6} \mathrm{Wat} / \mathrm{m}^{3}$ Brain is assumed as a single layer Brain Phantom model in which brain is considered as centre radius of sphere of $10 \mathrm{~mm}$ radius and placed in contactwith upper part of the antenna, dielectric constant of brain is assumed as 45.8.it gives a return los with brain model is $31.89 \mathrm{~dB}$ at $7.61 \mathrm{GHz}$ and current density is $801.24 \mathrm{Am}^{2}$, SAR of the brain phantom model with antenna is $3.15 * 10^{6}$ $\mathrm{Watt} / \mathrm{m}^{3}$.Now triangular hape tumor is assumed with dielectric constant of the tumor is 52.06 and it gives a return loss with tumor 32.26 at $7.544 \mathrm{GHz}$.current density with tumor is $960.3 \mathrm{~A} / \mathrm{m}^{2}, S A R$ of the phantom model with tumor and antenna is $3.069 * 10^{6} \mathrm{~A} / \mathrm{m}^{2}$.The paper dete t tumors by thee different parameter simultaneously that is very important aspect.
\end{abstract}

Keywords: Brain tumor, ultra wide band (UWB),Return loss(RL),Brain Phantom model

\section{Introduction}

Patch antennas are used as simple and for the widest and most demanding applications in world's wireless communication. They are famous due to their compact design, easy fabrication considerable gain and directivity although its bandwidth is increased by the applying different methods to the patch antenna like by applying different type of slot to the antenna and by applying different type of different ground structures like H,E dumbbell shape etc. Planner antenna are easy fabricate and easily mountable to any surface that's why these antennas are increasing their popular in today's world. in the figure below shows the radiations from the side edge.[1]-[3] A Micro strip patch antenna is very simple in the construction using a conventional Micro strip fabrication technique, all the things ground plane, substrate, antenna top head is represented in Figure 1 given below. 


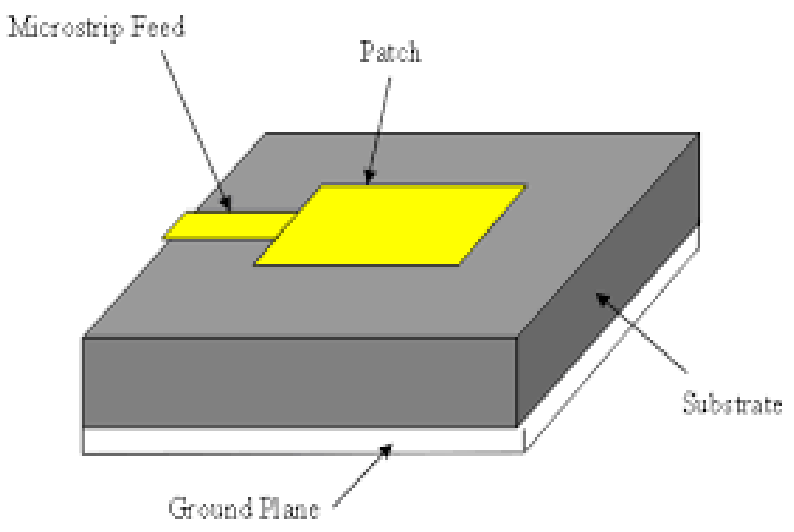

Figure 1. Rectangular Microstrip Patch Antenna

A medical application of the Microwave imaging is used to detect the tumor in any body part. In detection of brain tumor in which antenna is placed in contact with the brain and reflected signal is observed and current density is found much higher in the brain with tumors this is called brain tomography. As a new option microy ave imaging is a new and safer technique in comparison to the X-ray mammography in the paper gauss Newton algorithm is used to solve the problem [4]

The antenna used in this methods is novel ultra wide band antenna that can operate from $2.6 \mathrm{GHz}$ to $13.1 \mathrm{GHz}$.The generated $\mathrm{S}$ parameter of frequency domain converted into the time domain by inverse Fourier transform, In the paper microwave imaging system simulation for brain tumor detection system is presented. The platform to solve the problem is CST. The detection methods based or the detection of differences in scattering parameters. [5]

A Vivaldi antenna for brain cancer detection is presented. a phantom model with dielectric properties of a brain is designed. The radiation pattern of a UWB Vivaldi antenna has been exposed to the human head model. specific absorption rate by electromagnetic wave is calculated it is found that SAR is much greater in human head with tumor as compared to the human head without tumor. [6]

Antenna is fabricated with FR4 substrate and it is found good matching between head tissue. Antenna is designed to operate in $100 \mathrm{MHz}$ to $1.4 \mathrm{GHz}$.result shows that good performance is obtained for the design size $329.25 \times 153 \times 1.6 \mathrm{~mm}$.[7]

Vivaldi Structure is shown for brain tumor detection the radiation is investigated in human head phantom model with tumor. [8]

In the paper new holography microwave imaging array techniques for brain cancer detection is presented. This technique is based on holographic microwave and aperture synthesis imaging system.[9]

Microwave imaging is an inexpensive non-invasive modality of media dielectric that can be used in brain tumor and breast cancer detection. For breast cancer detection the ite ative algorithm of structural inversion with all boundaries defined, but in case of brain tumor detection inversion problem is much more difficult due to the skull that produce more noise. [10]Method has been applied to the $2 \mathrm{D}$ slices created from a database of $3 \mathrm{D}$ real MRI phantom images. Cancerous tumor of $5 \mathrm{~mm}$ and its four layers simulated with CST microwave studio. Pulse is applied to the brain model and pulse receive by the receiver antenna has been analyzed. the analytical signal function has been employed to reduce the noises and scanning method is applied for microwave imaging which shows the good agreement between actual and detected tumor location. [11]

In the paper wideband compact tapered microstrip feed antenna is presented for brain tumor detection .antenna is immersed in high coupling liquid that is use for higher signal penetration into the brain. [12] 
Antenna array consist of three Vivaldi antennas. a brain model with four layers is created and simulated. a radius of $5 \mathrm{~mm}$ tumor is modeled and signal is input to the brain having tumors and reflected signals from tumors studied. [13, 15]

In the paper array of oval patch antenna is presented so that it can be fit into the chamber of breast. Chamber size is $100 * 100 * 100 \mathrm{~mm}^{3}$. Result shown in the paper less than $-10 \mathrm{~dB}$ response at 2.7 to $5 \mathrm{GHz}$ according to the chamber there is a designed a $3 * 3 * 3$ antenna array for a chamber. [14]

\section{1. .Microwave Imaging}

Microwave imaging principal is utilized to detect the tumor in the brain. Reflected signals also reflected from various part of the brain which is undesirable. It is desirable that signal should reflect only from tumors so antenna placed in contact with the brain. In the paper tumor is detected by the three different parameter namely return loss, current density, and Specific absorption rate, simultaneously.

\section{Antenna Design \& Simulation Results}

For Designing an Ultra wide band antenna first of all antenna is designed on that one frequency of the band. After that apply different DGS nethod to make a band wideband and is considered Ultra wide band if and only if the bandwidth is greater than 500MHz.Antenna design is done using CST-Microwave Studio 2014 simulation software and the parameters are displayed by the figures The Ground plane is modified to make the antenna ultra wide band, The Length and Width of Antehna has been calculated by the formula given in books [15], and all the slot out into the front of the antenna find out by the number of iteration on the simulation software The ground plane is modified by the different DGS patterns as shown in figures belom for the number of iteration the simulation software and dimensions are stored for the best result.

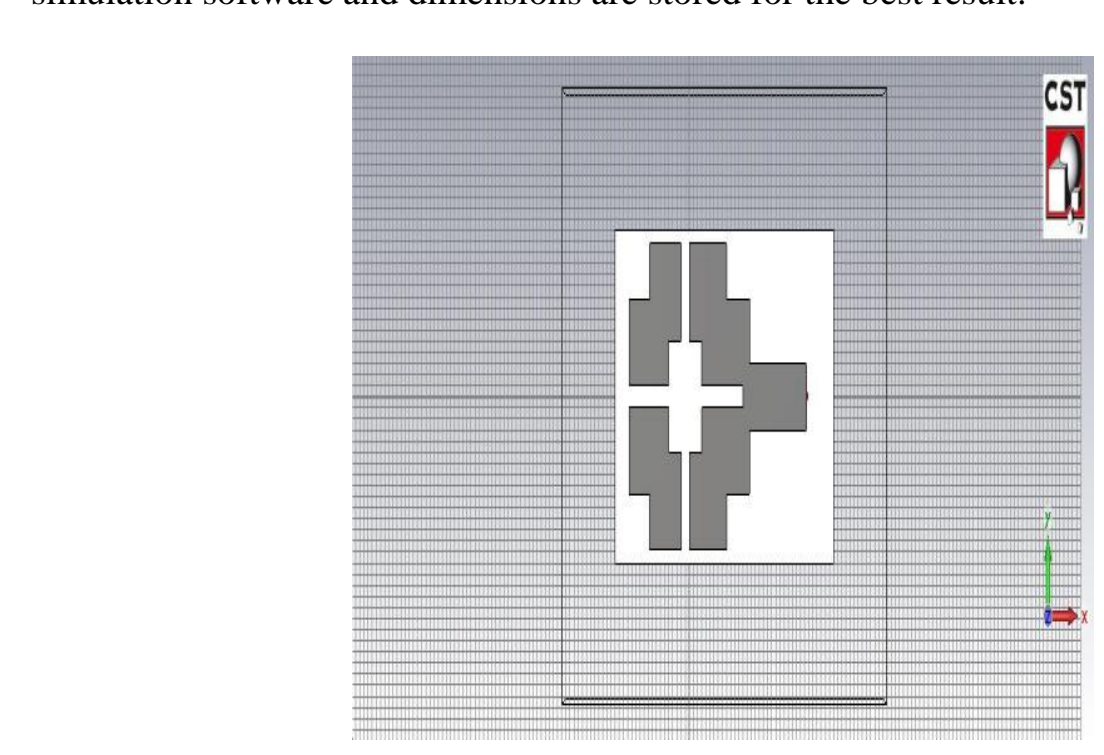

Figure 2. Front View of UWB Planner Antenna 


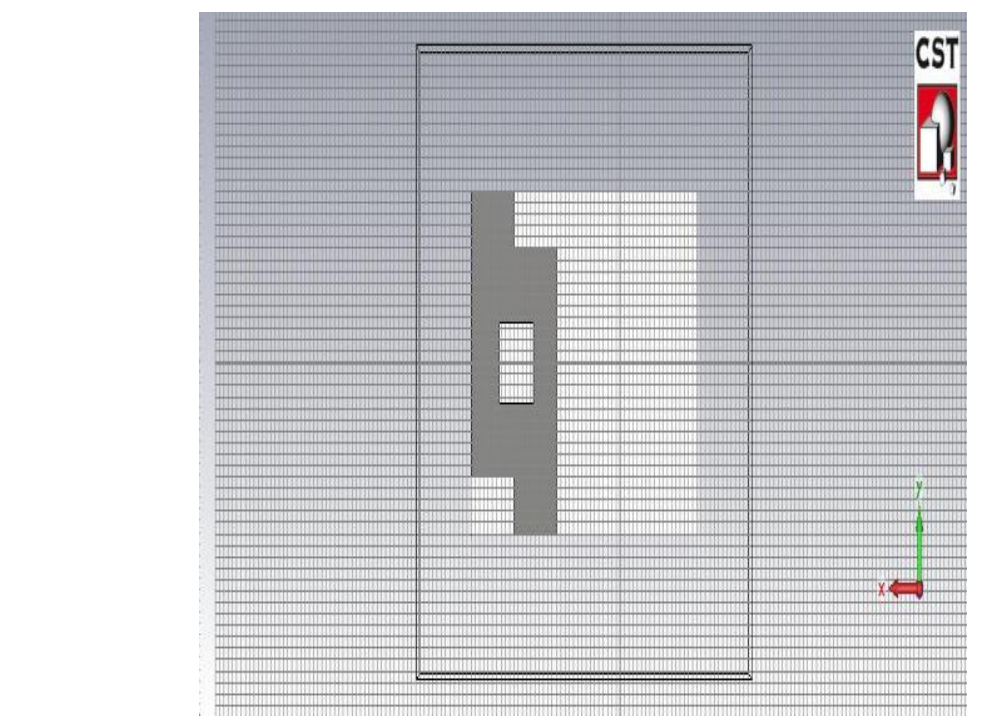

Figure 3. Modified Ground Plane of the UWB Planner Antenna

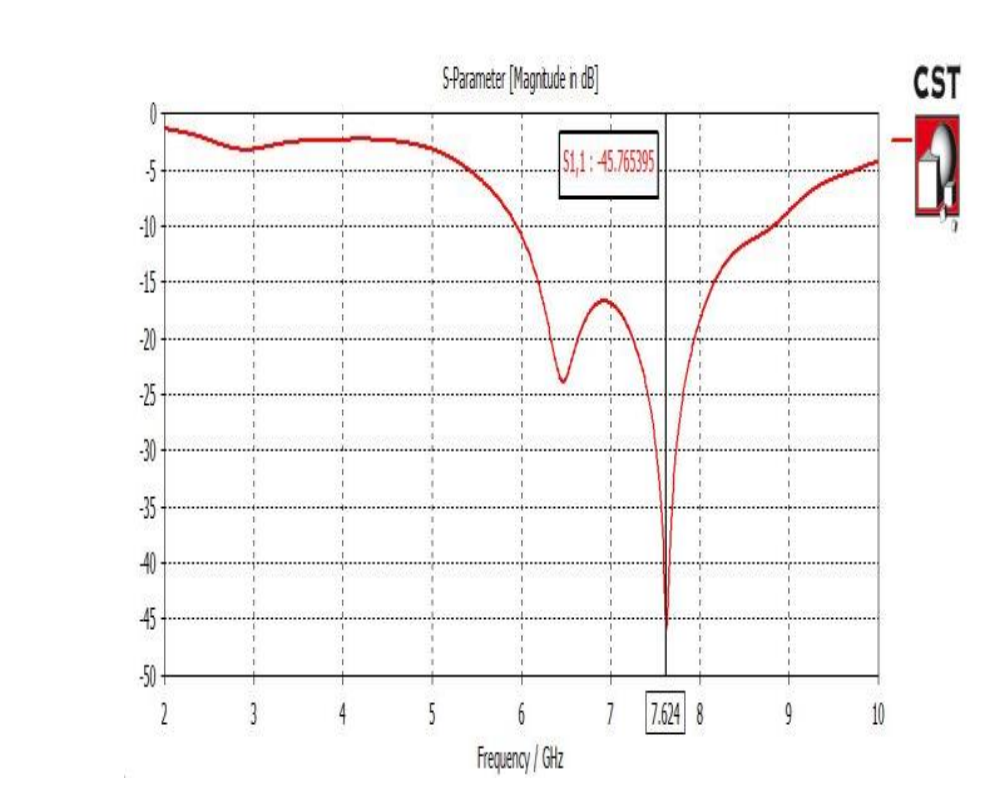

Figure. 4. Returh Loss of the UWB Planner Antenna $45.76 \mathrm{db}$ at $7.624 \mathrm{Ghz}$ 


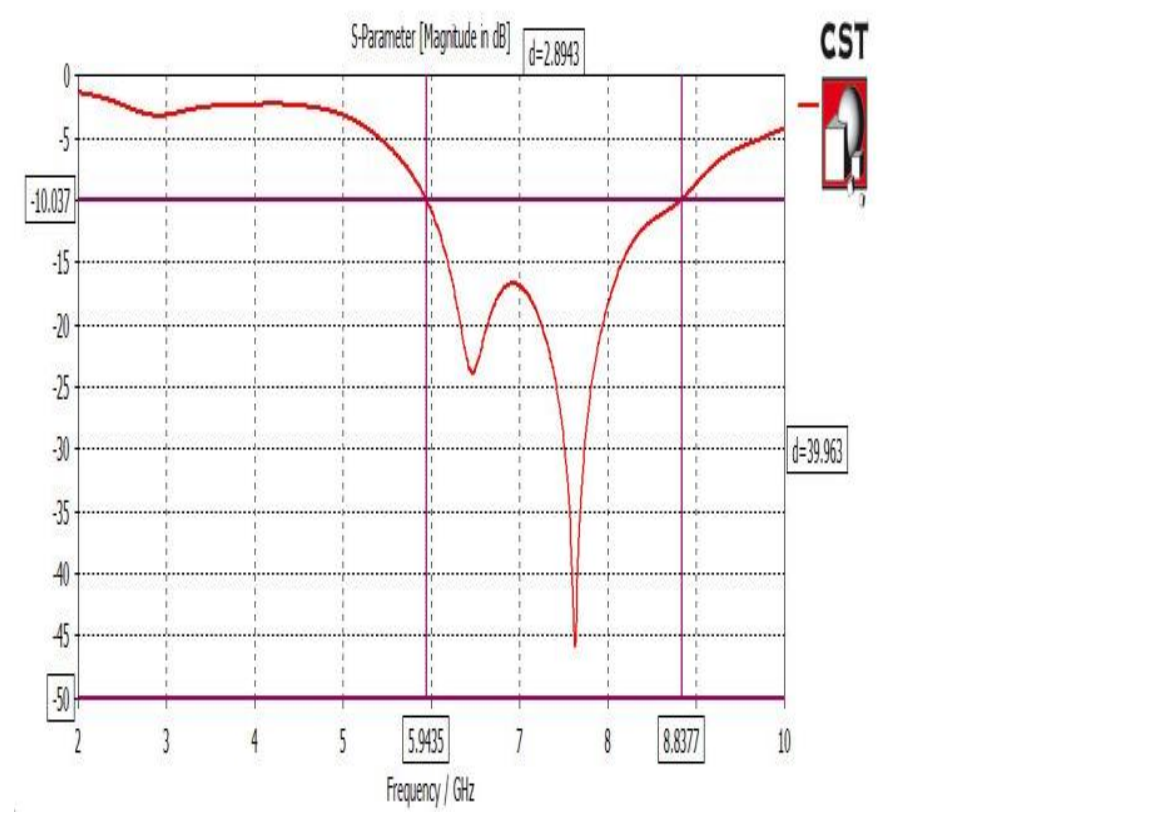

Figure 5. Bandwidth of the Planner UWB Antenna Is $2.8493 \mathrm{Ghz}$

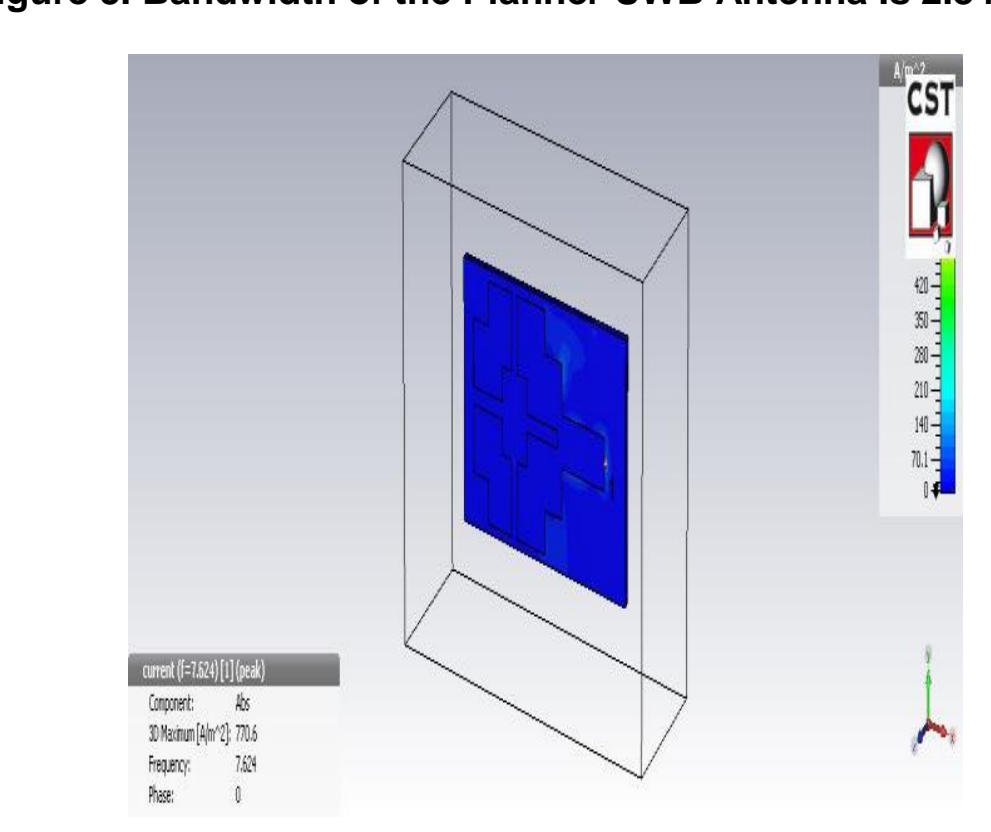

Figure 6. Current Density of Miniaturized UWB Antenna Is $770.6 \mathrm{~A} / \mathrm{M}^{2}$

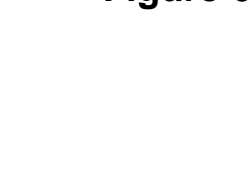




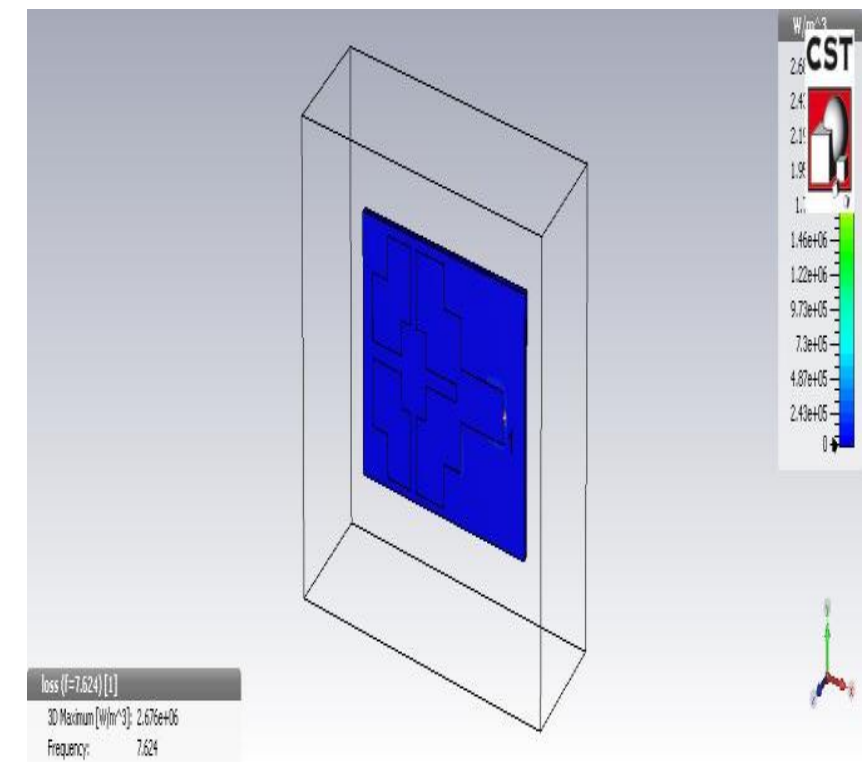

\section{Figure 7. Specific Absorption Rate Produced by Planner UWB Antenna Is $2.67^{*} 10^{6} \mathrm{~W} / \mathrm{m}^{3}$}

It is very clear from above figures that plamer UWB antenn is designed with different symmetrical slots shown in Figure 2 its ground plane is modified by different DGS structures shown in Figure 3.return loss or then anten shown in Figure 4.it is shown in figure5 that approximate bandwidth of the antenna Is $2.8493 \mathrm{GHz}$.current density is $770.6 \mathrm{~A} / \mathrm{m}^{2}$ clear from Figure 6.From Figure 7 its SAR is $2.67 * 10^{6} \mathrm{w} / \mathrm{m}^{3}$.In next section the brain model is designed by CSF-MWS and it is placed in contact with antenna and all parameter of the system will discussed. Results are compared with the brain phantom model when brain model wh tumor is placed with antenna.

\subsection{Brain Phantom Model}

Model of the brain is represented by a sphere with $10 \mathrm{~mm}$ centre radius and $5 \mathrm{~mm}$ top and botton radius. Its dielectric permittivity $=45.8$ and conductivity $=.77 \mathrm{~s} / \mathrm{m}$, A Cancer Tissue is assuned by a cube of $5 \mathrm{~mm}$ side face. Its dielectric properties chosen as an cancer tissues Dielectric Constant $=54.06$ and Conductivity $=2.62 \mathrm{~s} / \mathrm{m}$

There will be considering two different conditions. They are first brain phantom model with UWB antenna. all parameter will discuss. Second condition is the brain phantom model with tumor is represented with UWB antenna and all parameter will discuss. Comparing both conditions parameters to detect the tumors.

Now all things display by the simulation figures below 


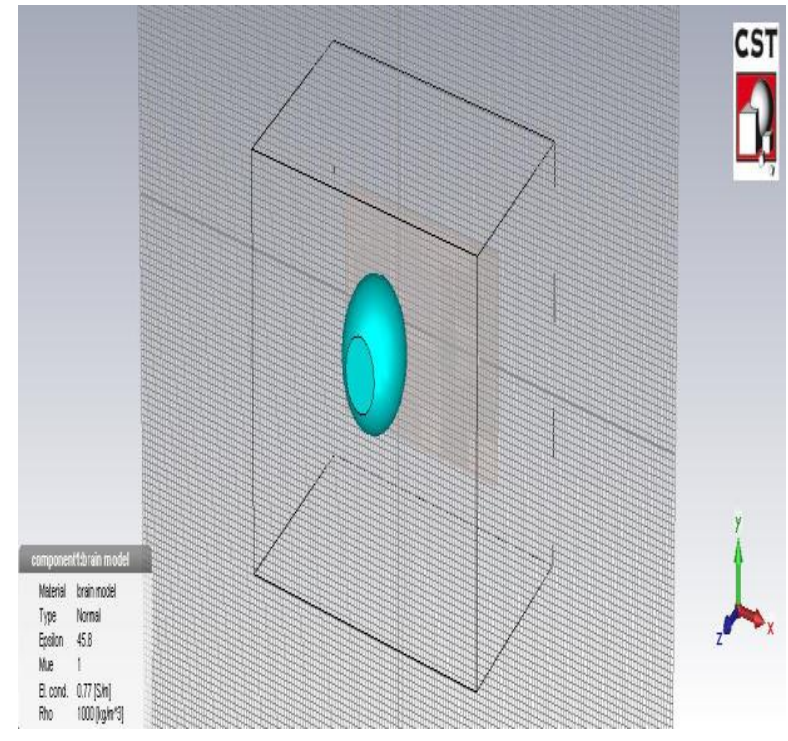

Figure 8. Perspective View of the Brain Phantom Model with UWB Antenna

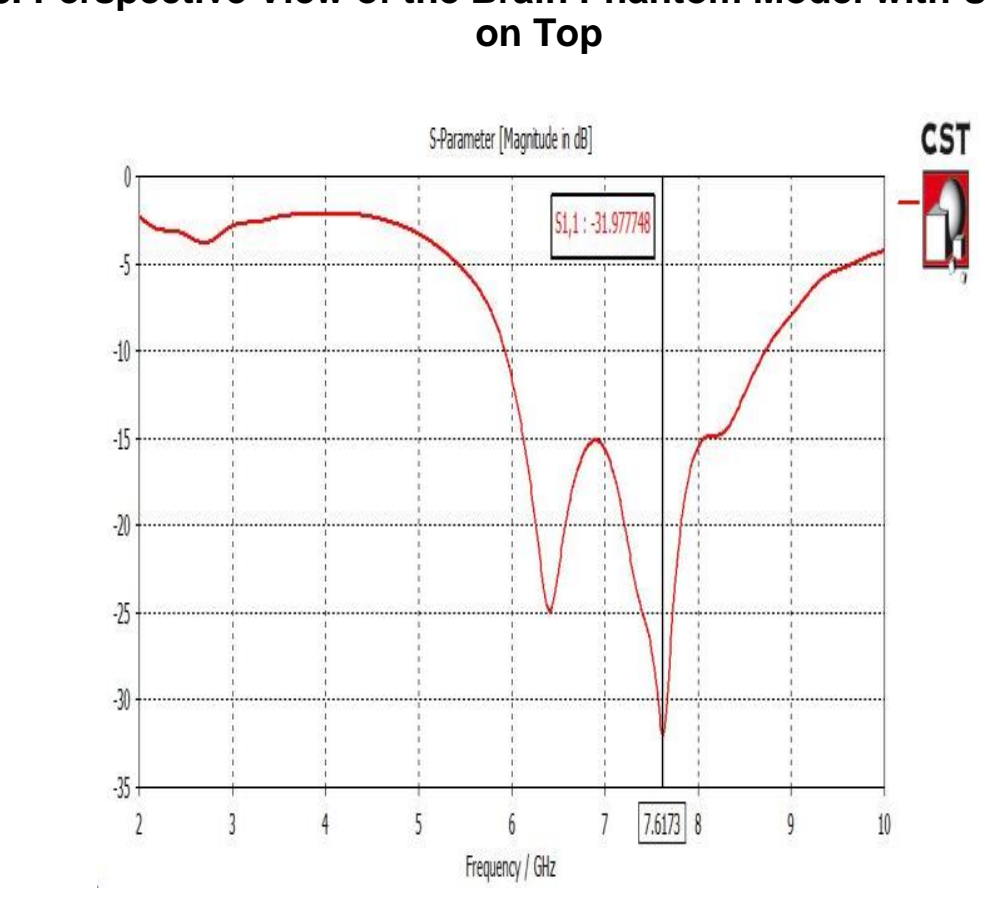

Figure 9. Return Loss of Brain Phantom Model with Miniaturized UWB

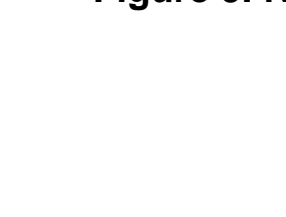

Antenna Is $31.97 \mathrm{db}$ at $7.6173 \mathrm{Ghz}$ 


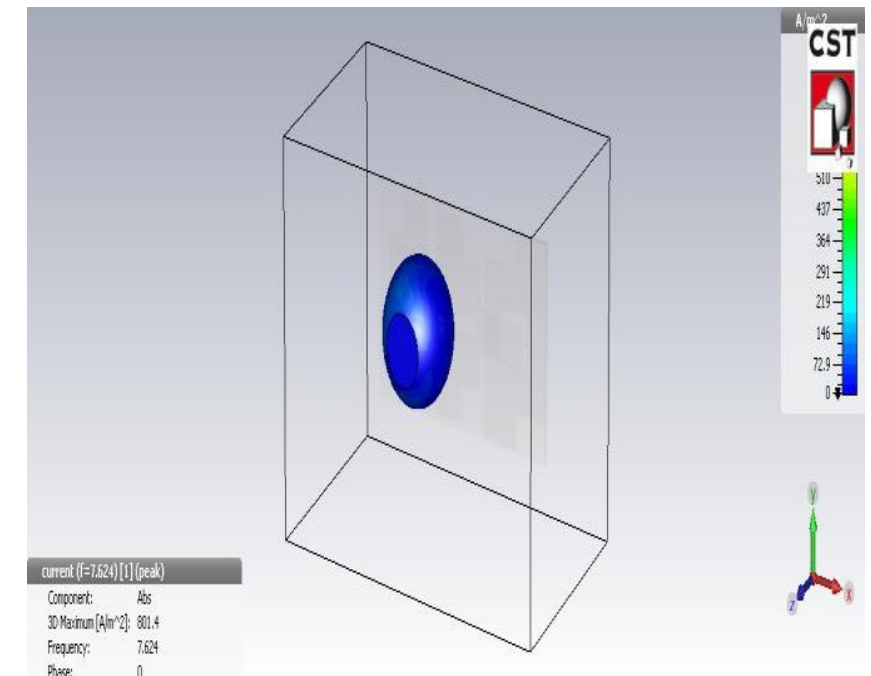

Figure 10. Current Density of Miniaturized UWB RMPA with Brain Phantom

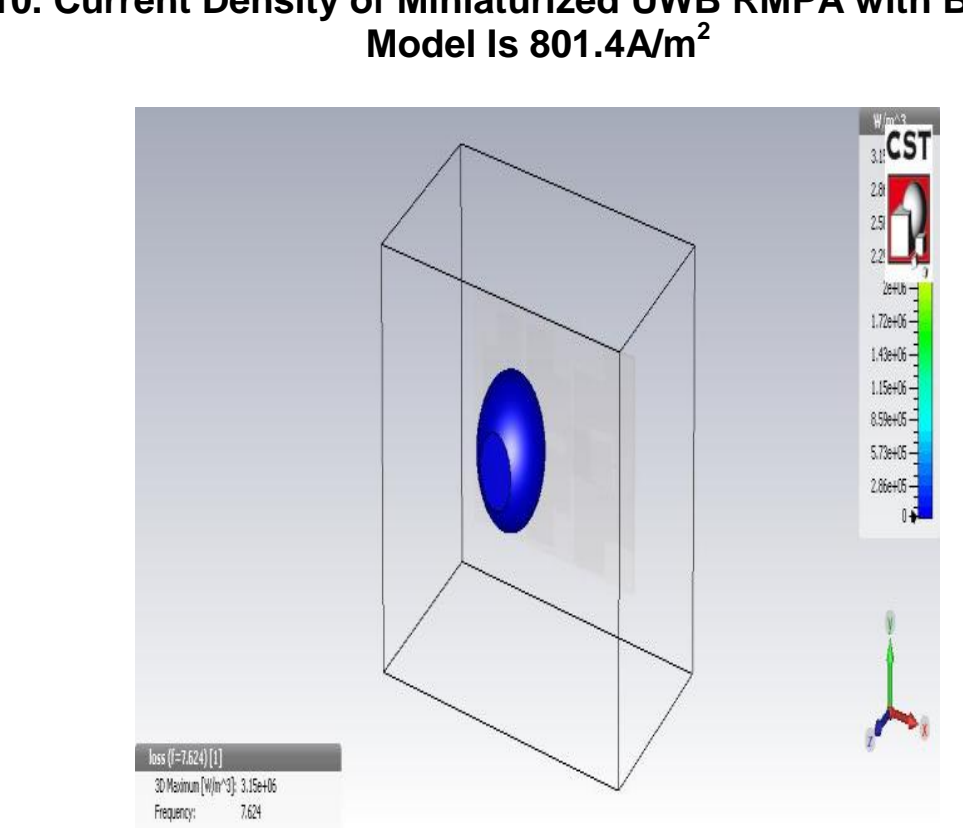

Figure 11. SAR of Miniaturized UWB Antenna with Brain Model Is $3.15^{\star} 10^{6}$

Table 1. Shows the Results of Brain Phantom Model with Miniaturized Ultra Wide Band Antenna

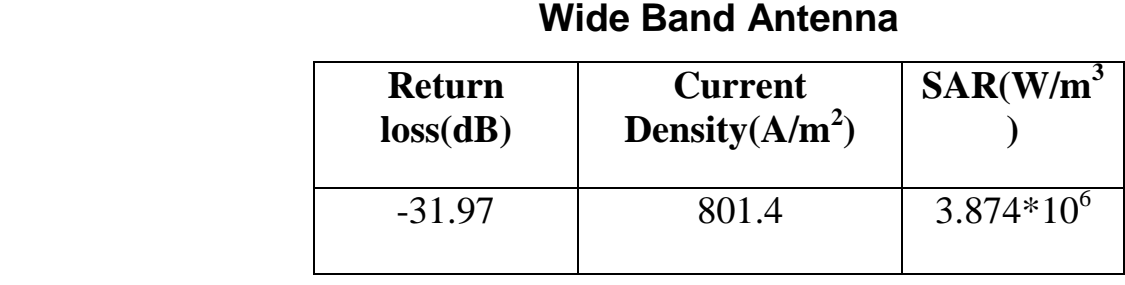

It can easily be seen from above figure that Figure 8 is showing brain phantom model. Figure 9 shows the return loss and Figure 10 shows the current density of the system. Figure 11 shows the SAR of the system. Current density is much higher it is $801.4 \mathrm{~A} / \mathrm{m}^{2}$ as Compared to the miniaturized UWB antenna alone. Now tumor in the brain model is represented by triangular tumor and all the parameters will be display by the figures. 


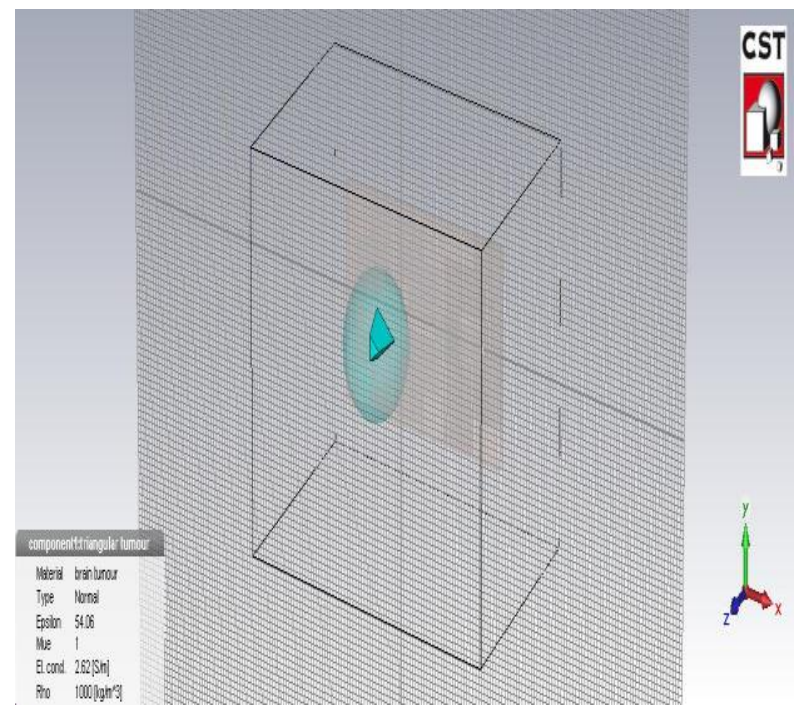

Figure 12. Perspective View of the Brain Phantom Model with Triangular Tumor at Center of the UWB Antehna

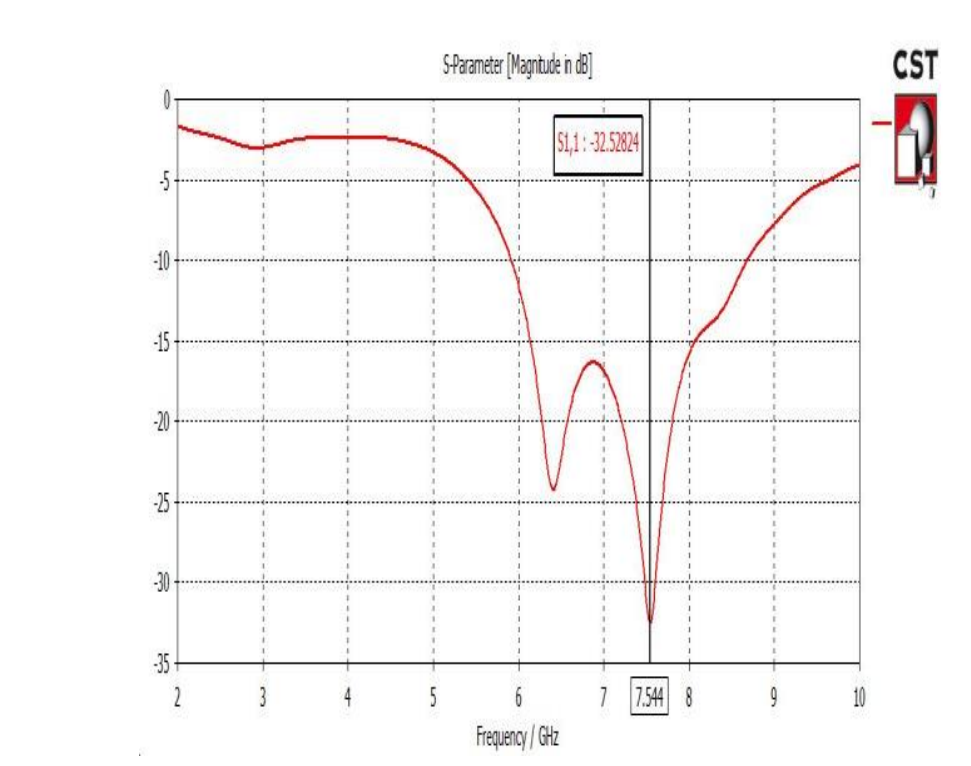

Figure 13. Retarn Loss of Brain Phantom Model with Cancer Tumor in the

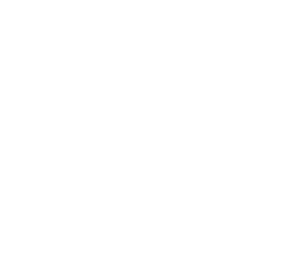

Center Is 32.52db 


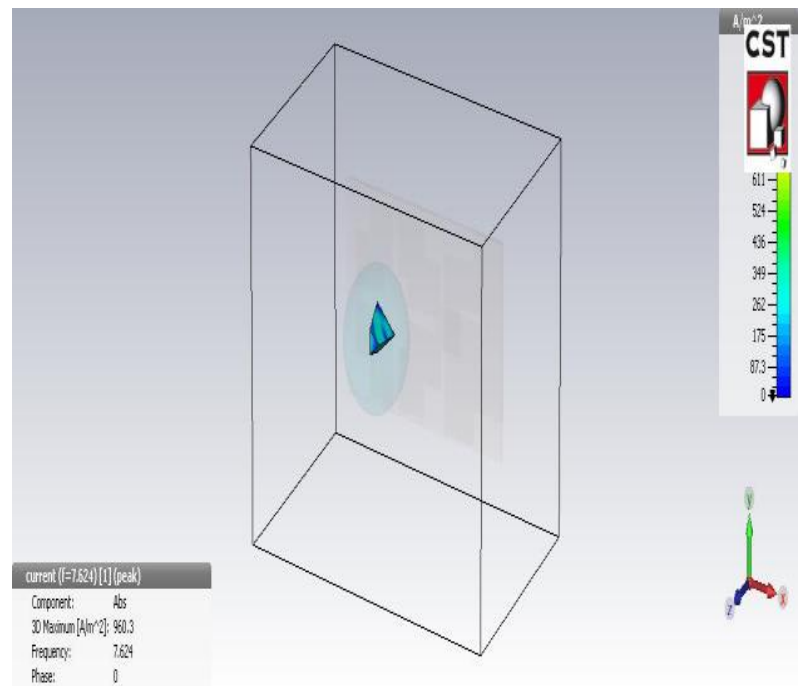

Figure 14. Current Density of Miniaturized UWB Antenna with Tumor in the Center of the Brain Is $960.3 \mathrm{~A} / \mathrm{m}^{2}$

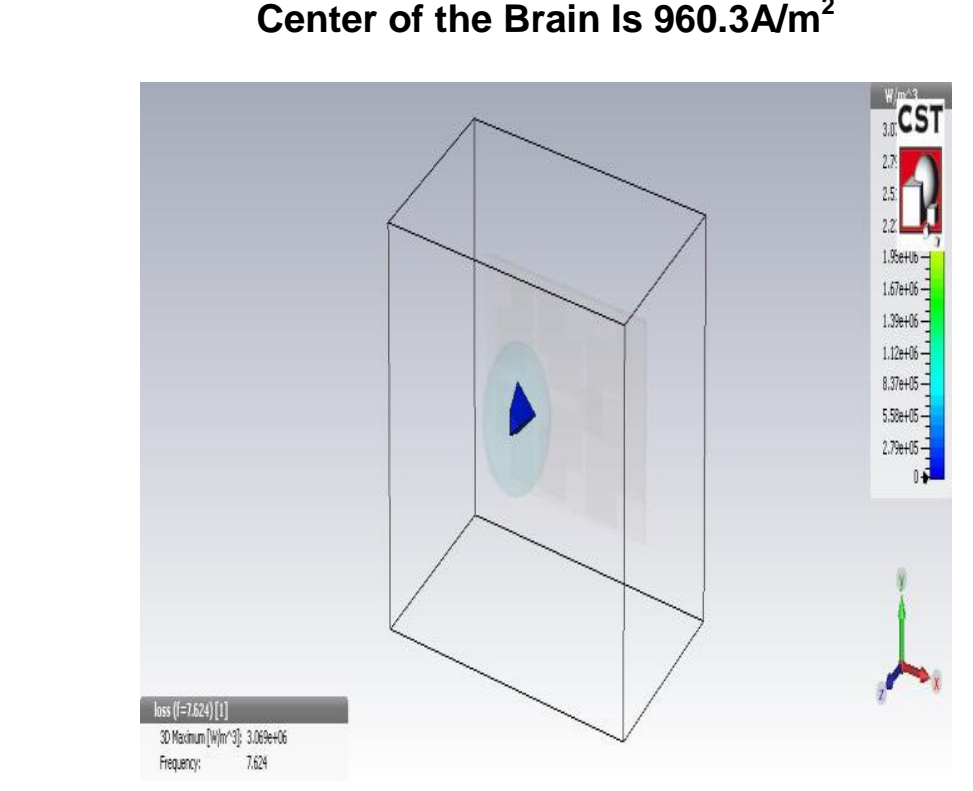

Figure 15. SAR of the System with Triangular Shaped Tumors

Modeled tunor with brain phantom model is shown in Figure 12. Figure 13 shows the return loss of the system with tumor. Figure 14 shows the current density of the system and Figure 15 shows the SAR of the system.

Table 2. Brain Phantom Model with Triangular Tumor in the Center

\begin{tabular}{|c|c|c|}
\hline Return loss(dB) & $\begin{array}{c}\text { Current } \\
\text { Density }\left(\mathbf{A} / \mathbf{m}^{2}\right)\end{array}$ & $\begin{array}{c}\text { SAR( } \\
\mathbf{W} / \mathbf{m}^{3}\end{array}$ \\
\hline-32.26 & 960.3 & $3.069^{*}$ \\
& & $10^{6}$ \\
\hline
\end{tabular}

\section{Results and Discussion}

Ultra wide band planner Microstrip Patch Antenna with symmetrical Slot and modified ground plane has been designed and simulated in CST-MWS studio shown in figure. 2 and 3 . Bandwidth of the ultra wide band antenna is $2.84 \mathrm{GHz}$ that is enough to make it ultra 
wide band shown in Figure 5. Reflection coefficient in $\mathrm{dB}$ shown in Figure 4 that is $45.76 \mathrm{~dB}$ at $7.24 \mathrm{GHz}$. There are one more frequency on which antenna is resonating all the parameter like current density and SAR are calculated for lowest reflection coefficient. The current density is shown in the Figure 6 it is $770.6 \mathrm{~A} / \mathrm{m}^{2}$.SAR produced by the antenna is $2.67 * 10^{6} \mathrm{~W} / \mathrm{m}^{3}$, shown in Figure 7 .

Now single layer brain phantom model is modeled by the sphere of centre radius $10 \mathrm{~mm}$ and top and bottom radius $5 \mathrm{~mm}$.tumor inside the sphere having the shape of triangle having the dielectric constant $=45.8$ and conductivity $=.77 \mathrm{~s} / \mathrm{m}$.brain model shown in the Figure 8 and its return loss shown in Figure 9. The approximate bandwidth of the system $2.8493 \mathrm{GHz}$ and its current density shown in Figure 10 which is $801.4 \mathrm{~A} / \mathrm{m}^{2}$ . SAR of the system is $3.15^{*} 10^{6}$ is Shown in Figure 11 .Brain with tumor model is shown in Figure 12. Reflection coefficient of the system is shown in Figure 13. it is clear that losses is decreased when the brain model is subjected to the tumor that because of less current signals reflected due to tumor in the brain. Current density with tumor is shown in Figure 14 is $961.2 \mathrm{~A} / \mathrm{m}^{2}$.SAR of the brain phantom model with triangular shaped tumor is shown in Figure 15 that is $3.069^{*} 10^{6}$.all the results can also be verified from the Table-1 and Table-2.

\subsection{Detection of Tumors by Three Parameter Simultaneously}

a. Current density is higher in the brain model with tumor that detects the presence of tumor clear from Figure 10 and Figure 14.

b. SAR of the system with tumors is slightly decreased it detect the presence of tumors clear from Figure 11 and Figure 15, also,veritied from table land table 2.

c. Return loss of the system with tumor decreased due to less number of reflected waves comes out due to the tumors in the brain, clean from the Figure 9 and Figure 13.

Future work is suggested to design more realistic brain model. One can use the multilayer brain model to approach the reality of the brain phantom model. It can be easily seen that the return losses are decreased with tumor, and it detect the presence of tumor and current density with tumor is increased because of the presence of the tumor and SAR of the system is very slightly reduced with tumor also indicate the presence of the tumor in the brain

The Novelty of the work dône in this research paper is this system is capable for brain tumor detection by three different parameter simultaneously.

\section{References}

[1] R. Bancroft, "Mieros rip and Printed Antenna Design Noble Publishing 2004", chapter 2-3.

[2] Y.T. L o, D. Solomon and W.F. Richards, "Theory and Experiment on Microstrip Antennas", IEEE Transactions on Antennas and Propagation, AP-27, (1979), pp. 137-149.

[3] D. M. Pozar and D. H. Schaubert, "Microstrip Antennas: The analysis and Design of Microstrip Antennas and Arrays", IEEE Press, Piscataway, NJ, (1995).

[4] S.-H Son, N. Simonov, H.-J. Kim, J.-M. Lee and S.-I. Jeon, "Preclinical Prototype Development of a Micjowave Tomography System for Breast Cancer Detection”, in ETRI journal, vol. 32, no. 6, (2010), pp. $901-910$.

5. M.A. Jamlos1, M.F. Jamlos2, A.H. Ismail3, "High Performance Novel UWB Array Antenna for Brain Tumor Detection", by Scattering Parameters in Microwave Imaging Simulation System in Antennas and Propagation (EuCAP), 9th European Conference on 13-17 April, (2015), pp. 1-5.

[6] J. Jasmine Angle and T. Anita Jones Marry, "Design of Vivaldi Antenna brain Tumor Detection", International Conference on Electronics and Communication Systems (1CECS -2014), Coimbatore, INDIA, (2014).

[7] M. A. Alzabidi, M. A. Aldhaeebi and I. Elshafiey, "Optimization of UWB Vivaldi Antenna for Tumor detection", in First International Conference on Artificial Intelligence, Modelling \& Simulation Riyad Saudi Arbia, (2014).

[8] L. Wang1, A. M. Al-Jumaily1 and R. Simpkin2, "Holographic Microwave Imaging Array for Brain Stroke Detection", in Journal of Signal and Information Processing, vol. 4, (2013), pp. 96-101.

[9] N. Irishina and A. Torrente, "Brain Stroke Detection by Microwaves", Using Prior Information from Clinical Databases in Hindawi Publishing Corporation, vol. 2013, (2013), pp. 8 
[10] H. Zhang, B. Flynn, A. T. Erdogan, T. Arslan, "Microwave Imaging for Brain Tumor Detection Using an UWB Vivaldi Antenna Array in Loughborough Antennas \& Propagation Conference", Loughborough, UK, (2012).

[11] B. J. Mohammed*, A. M. Abbosh, D. Ireland and M. E. Bialkowski, "compact wideband antenna immerssed in optimum coupling liquid for microwave imaging of brain stroke", in Progress In Electromagnetics Research C, vol. 27, (2012), pp. 27-39.

[12] H. Zhang, A. O. El-Rayis, N. Haridas, N. H. Noordin, A. T. Erdogan and T. Arslan, "A Smart Antenna Array for Brain Cancer Detection", in Loughborough Antennas \& Propagation Conference 14-15 November, Loughborough, UK, (2011).

[13] J. Yu y, M. Yuan and Q. H. Liu, "A Wideband Half Oval Patch Antenna for Breast Imaging”, Progress In Electromagnetics Research, vol. 98, (2009), pp. 1-13.

[14] C. Balinies, “Antenna Theory”, Wiley, 2nd addition chapter -14 ISBN 0-471-59268-4, (1997).

[15] V. Singh Kushwah and G. S. Tomar, "Size reduction of Microstrip Patch Antenna using Defected Microstrip Structures", IEEE International Conference on Communication Systems and Network Technologies CSNT 2011, (2011), pp. 203-206.

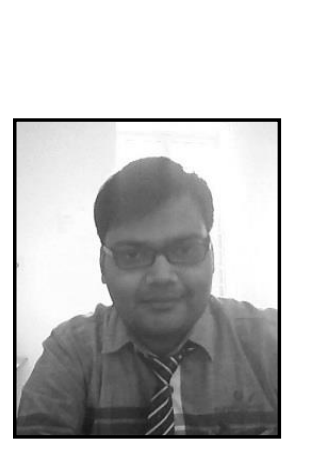

\section{Authors}

Hemant Kumar Gupta, he completed his Bachelor of Engineering (Electronics Communicâtion) fron Samrat Ashok Technological Institute Vidisha (M.P)-INDIA In dration 20032007,and Completed his Master of Engineering(Communication Control Networking)In duration 2010-2012 from Madhav Institute of Technology Science Gwalior (M.P)-474005 INDIA, his area of research are Microstrip Patch Antenned Designs with Defect Ground Structures, his favorite teaching subjects are Data Communication, Cellular and Mobile-Communteation and Analog and Digital Communication and Electromagnetic Theory. Author also published one book title" fact and formulas for Electronics and Communicalon engineering" with Lambert academic Publisher US in 2015.He published bis 12 research papers in highly reputed international journals

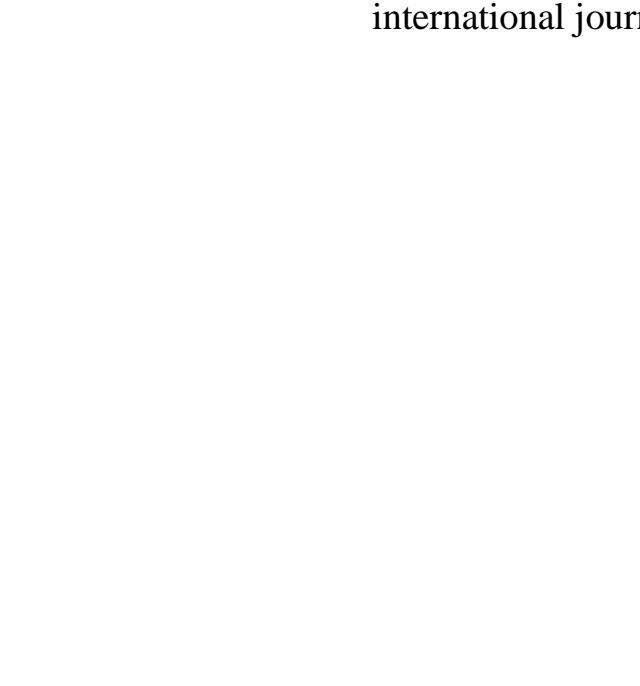

